EFI, EKONOMISKA FORSKNINGSINSTITUTET
VID HANDELSHÖGSKOLAN I STOCKHOLM

Trading Volume and Autocorrelation:

Empirical Evidence from the

Stockholm Stock Exchange

Patrik Säfvenblad

Working Paper No. 191

September 1997

Working Paper Series

in Economics and Finance 



\title{
Trading Volume and Autocorrelation: Empirical Evidence from the Stockholm Stock Exchange
}

\author{
Patrik Säfvenblad* \\ Stockholm School of Economics \\ Department of Finance
}

September 1, 1997

Working Paper Series in Economics and Finance No. 191

\begin{abstract}
This paper provides an extensive empirical investigation into the sources of index return autocorrelation, focusing on the relation between autocorrelation in individual stock returns and autocorrelation in index returns. The study uses daily data from the Stockholm Stock Exchange over the period 1980-1995 and reports three main empirical findings.

Daily Swedish stock index returns exhibit strong, and consistently positive, first order autocorrelation throughout the sample period. Positive autocorrelation is observed for return frequencies between 1 day and 3 months.

The most liquid stocks exhibit strong positive return autocorrelation. Less liquid stocks exhibit weak or negative return autocorrelation. Autocorrelation is asymmetric, high after days of above average performance of the stock market, low after days of below average performance. When compared to the other days of the week, both index returns and individual stock returns exhibit the strongest autocorrelation following on Friday returns.

The transaction cost hypothesis was tested using the Swedish stock market transaction tax. Results indicate lower precision of stock prices during the transaction tax period, but no direct effect on return autocorrelation.

The paper concludes that at least three sources contribute to observed return autocorrelation. For daily and short-term returns, profit taking and nonsynchronous trading are the probable causes of observed autocorrelation. For monthly and longer term returns, time-varying expected returns best describe the empirical results.
\end{abstract}

*The paper has benefitted from comments made by Clas Bergström, Bevan Blair, Magnus Dahlquist, Yrjö Koskinen, Lars Nordén, David Smith, Staffan Viotti, and seminar participants at the Stockholm School of Economics, at the "Nordic symposium on corporate and institutional finance," Oslo, June 1995, and at the "Arne Ryde workshop on asset pricing," Lund, November 1995. I gratefully acknowledge research funding from Bankforskningsinstitutet. Address: Box 6501, S-113 83 Stockholm, Telephone: +46-8-736 9000, Fax: +46-8-31 23 27, Internet E-mail: finpsa@hhs.se. 


\section{Introduction}

It is well documented that daily stock index returns are positively autocorrelated. Positively autocorrelated returns are observed in most stock markets and for a wide range of return frequencies, from intraday to monthly data. This is contrary to most theoretical models of market efficiency, which generally require returns to be serially uncorrelated.

In an influential article, Boudoukh et al. (1994) discuss three explanations for the persistent index return autocorrelation. The causes mentioned are nonsynchronous trading, time-varying risk premia and (irrational) investor underreaction or overreaction. The authors conclude that nonsynchronous trading effects can explain most of the observed return patterns in us data.

Although nonsynchronous trading is clearly an important factor for index return autocorrelation, it is widely accepted that nonsynchronous trading must be complemented with other sources of autocorrelation to explain observed levels of autocorrelation (often in the $0.10-0.25$ range)

In addition to the causes discussed by Boudoukh et al. (1994) there are several others, including transaction costs, cross-security information aggregation and bounded rationality. As no single theoretical model can account for the remaining autocorrelation, it is interesting to analyse the properties of autocorrelation on the Stockholm Stock Exchange.

Short-term returns on other similar assets, such as index futures and individual stocks, rarely exhibit positive return autocorrelation. The only difference between the calculated cash index and the price of an index future is that the latter is a traded asset. Thus the source of the short-term index autocorrelation must be searched in the microstructure of stock trading and index composition.

In this paper, the properties of individual stock returns are explicitly compared to those of index returns. The comparison provides a better understanding of the sources of autocorrelation for both types of returns.

This paper is structured as follows. The next section (section 2) briefly reviews some theoretical models that have implications for return autocorrelation. Section 3 discusses some earlier empirical evidence and presents new empirical results from the Stockholm Stock Exchange and section 4 summarises the findings of the paper.

\section{Background - causes of autocorrelated re- turns}

\subsection{Nonsynchronous trading and sampling errors}

Nonsynchronous trading adds autocorrelation to observed stock index returns. This has been modelled by, for example, Fischer (1966), Scholes and Willams (1977) and Lo and MacKinlay (1990a). In a pure nonsynchronous trading model, it is assumed that stock returns are continuous processes sampled whenever the stocks are traded. As all stocks do not trade simultaneously (synchronously), there will be some outdated stock prices in a compiled stock index. These old prices will lead to a delay in the observation of market factors. If nontrading probabilities are constant, the measured index return will follow an AR(1)process with positive first order autocorrelation (Lo and MacKinlay, 1990a). 
Several papers test the empirical relation between nonsynchronous trading and index return autocorrelation. Lo and MacKinlay (1990a) conclude that the level of nontrading in their sample cannot explain more than part of the observed index return autocorrelation. ${ }^{1}$

Atchison et al. (1987) calculate the autocorrelation induced by nonsynchronous trading for portfolios of NYSE stocks. The authors report an autocorrelation coefficient due to nonsynchronous trading of $0.02-0.04$, which is far from, and significantly less than, the observed autocorrelation of 0.13-0.30. Berglund and Liljeblom (1988) investigate whether nonsynchronous trading is the cause of the very high autocorrelation in a value-weighted Finnish stock index $(0.49)$. They too conclude that nonsynchronous trading only explains a part of the observed index return autocorrelation.

A further problem with the nonsynchronous trading hypothesis is that the time series behaviour of index return autocorrelation differs from the model's predictions. McInish and Wood (1991) study the autocorrelation in daily returns, measured at different points in time during the day. During the active trading at open and close, nonsynchronous trading will have less impact on measured returns. Therefore, open-to-open and close-to-close returns should be less autocorrelated than midday-to-midday returns. However, McInish and Wood show that, contrary to the nonsynchronous trading hypothesis, index return autocorrelation is significantly higher when trading is active, that is, at open and close.

Although nonsynchronous trading cannot account for more than part of the observed index return autocorrelation, it is still an important factor, especially when considering less liquid markets, such as the Stockholm Stock Exchange. Fortunately, nonsynchronous trading effects are independent of other sources of autocorrelation, including time-varying expected returns, transaction costs and information revelation. Therefore, it is possible to model observed levels of index return autocorrelation as a sum of effects from nontrading and other contributing factors.

\subsection{Return autocorrelation in a rational expectations equi- librium}

In the nonsynchronous trading model, prices are explicitly modelled as efficient, and returns on individual stocks are therefore not serially correlated. The most common type of model leading to such prices is the rational expectations equilibrium (REE). In such an environment, trading and prices are modelled as the result of a Nash equilibrium in demand strategies.

Resulting prices efficiently aggregate all public information and all information revealed by net demand at equilibrium prices. If the market is competitive, prices will follow a random walk. This is the case, for example, in the auction market model of Hellwig (1980) and the market maker model of Kyle (1985).

In the case of a non-competitive market, explored theoretically by Kyle (1989), rational traders without private information can expect to earn positive profits by providing liquidity to the market. This will result in observed prices

\footnotetext{
${ }^{1}$ Boudoukh et al. (1994) discuss the possibility of generating high index return autocorrelation by assuming extreme nontrading patterns. However, there is no empirical support for the existence of such nontrading patterns.
} 
being negatively autocorrelated, imposing transaction costs on non-informational trades. $^{2}$

In the market maker setting, this negative autocorrelation is often called bid-ask bounce. In periodic auction markets there are no formal bid and ask prices, but it is well known that realised returns exhibit return properties similar to bid-ask bounce. Although bid-ask bounce often causes strong negative autocorrelation in individual stock returns, it is only of limited importance for stock index returns. Most effects disappear in portfolios of as few as 10-20 stocks.

REE models, including Hellwig (1980) and Kyle (1985), rely heavily on the use of linear optimal demand schedules and pricing rules. Non-linearity will have important and hard-to-predict effects on optimal trading strategies, but the linearity assumption is of no importance for the resulting price dynamics. If markets are competitive, returns will be serially uncorrelated; if markets are non-competitive, returns will be negatively autocorrelated.

\subsection{Feedback trading}

Short-term returns in a non-competitive REE environment are strictly negatively autocorrelated. However, for longer return horizons, both positively and negatively autocorrelated returns can result, if the non-competitive market is combined with feedback trading. ${ }^{3}$ Feedback trading is the part of non-informational demand that can be predicted using observable variables, such as past returns.

Feedback trading includes several well-known trading strategies, such as profit taking, herding, contrarian investment and dynamic portfolio reallocation. A distinction is usually made between positive and negative feedback trading. In the case of positive feedback trading, traders buy after price increases (similar to herding), while in the case of negative feedback trading, traders sell after price increases (similar to profit taking).

A simplified model of feedback trading and return autocorrelation is developed by Sentana and Wadhwani (1992). The authors show that positive feedback trading results in negative return autocorrelation while negative feedback trading results in positive return autocorrelation. ${ }^{4}$

If traders react differently to price increases than to price decreases, the effect may be asymmetric. According to the prospect theory, agents are eager to realise profits, but unwilling to realise losses (Kahneman and Tversky, 1979). Since actual and implicit short selling restrictions leave the market with more "winners" after a day of good stock market performance, most profit taking should be expected after such days. As a result, autocorrelation in measured returns would tend to be more positive after price increases. If present, this effect should be visible both in individual stock returns and stock index returns.

\footnotetext{
${ }^{2}$ The negative autocorrelation is often used as a measure of transaction costs in a financial market. See Roll (1984).

${ }^{3}$ In a competitive REE environment, competition for order flow will lead to serially uncorrelated returns even in the face of feedback trading.

${ }^{4}$ The following example may clear the intuition. After a day of strong market performance, a number of traders are left with positive positions and profits that they wish to close before the trading day ends. This selling, negative feedback trading, will lead to a price pressure that will lead closing prices to be biased downward relative to public information. This bias will be recovered the following day, resulting in positive expected returns conditional on positive returns, i.e., positive return autocorrelation.
} 


\subsection{Cross-security information aggregation}

Chan (1993) and Säfvenblad (1997a), show that cross-autocorrelation in stock returns can result from the information realised in competitive REE prices. Both models analyse the difference between the efficient pricing of an individual security and the pricing of a large number of securities. If securities trade simultaneously, information revealed in one security will improve the precision of stock prices in general and the index level in particular. Säfvenblad (1997b) shows that the resulting price adjustment is symmetric in all stocks leading to index return autocorrelation. Autocorrelation will depend on the covariance structure of revealed information and price priors. Mostly, the model predicts positively autocorrelated index returns, but negative autocorrelation is also possible.

Index return autocorrelation will be low when price precision is high, for example, after a day of high trading volume. Measured autocorrelation will be high in periods of high trading volume and volatility. For the Swedish sample studied in this paper, cross-security information aggregation is less relevant due to the high nonsynchronicity of data. As effects predicted from nonsynchronous trading are similar, but usually weaker, it is impossible to separate the two effects empirically in a market where securities trade nonsynchronously.

\subsection{The role of trading volume}

In REE models, such as Admati and Pfleiderer (1988), trading volume is a measure of the amount of information revealed in trading. ${ }^{5}$ Therefore, prices realised in high trading volume are expected to be better estimates of the underlying, or "true," value of securities. In the same vein, Foster and Viswanathan (1993) show that trading volume is positively correlated with the precision of the informed trader's signal, and the resulting price precision. Similarly, in the model of Campbell et al. (1993), high trading volume makes the aggregate risk aversion more easily observable.

In models where the autocorrelation is the result of an information extraction process, such as Campbell et al. (1993), Chan (1993) and Säfvenblad (1997b), high trading volume lowers the expected return autocorrelation.

\subsection{The transaction cost hypothesis}

Cohen et al. (1980) and Mech (1993), discuss the effect of transaction costs on cross-security price discovery. It is argued that transaction costs hold back transactions aimed at exploiting cross-security price errors, thus slowing prices' reaction to new cross-security information. Mech (1993) analyses a market maker market where returns are driven by private information. When spreads are positive, informed traders will only trade when the expected profit from private information exceeds transaction cost. Therefore, private information will only be exploited if its price effects exceed the prevailing spread. There will

\footnotetext{
${ }^{5}$ Other sources of trading volume, such as portfolio rebalancing or liquidity trading, will generally only contribute small portions of total trading volume. Particularly, as noninformational demand "attracts" informed trading, such as in the models of Grossman and Stiglitz (1980) and Admati and Pfleiderer (1988). It can also be mentioned that new public information will only generate relatively low trading volume. The price effect is realised without trading, and portfolio rebalancing will be relatively small given that portfolios are close to optimal before the information event.
} 
thus be a delayed reaction to "small" market-wide information events, while "large" events will be efficiently reflected in prices.

This argument presumes that the provider of liquidity (the market maker) is passive, only observing the incoming order flow. Therefore, some of the market makers' transactions are made at inefficient prices. However, in an auction market, this argument loses much of its cutting power, as traders are also the providers of liquidity, when trading using limit orders. Optimally, informed agents will use a combination of limit and market orders to exploit their information. ${ }^{6}$ In most limit order markets, direct trading costs are not an issue since limit orders can be submitted and cancelled at virtually no cost.

\subsection{Time-varying risk premia}

Another way to explain autocorrelation in stock returns is to assume that the equity risk premia are time-varying. Campbell et al. (1993) model an economy where the aggregate level of risk aversion is mean reverting, but unobservable. The risk aversion must therefore be inferred from asset prices. In periods of high trading volume, agents' estimates of the market risk aversion is more accurate and thus the autocorrelation in stock returns is reduced.

However, in order to credibly affect asset returns, the speed of mean reversion must be low. Explaining autocorrelation in daily returns simply requires too strong a time variation in expected returns. Economically, the equilibrium expected return on risky assets is bounded below by the riskfree interest rate. However, empirical predictions from autocorrelation-based models often yield expected returns that are lower than the riskfree rate, or even negative. 7 Time-varying expected returns can thus only be considered an explanation for longer term returns.

An important property of time-varying risk premia is that returns and return autocorrelations should be consistent and visible in all assets, including index futures and individual stocks. ${ }^{8}$ If the autocorrelation in long-term returns is similar for index returns and individual stock returns, time-varying expected returns could provide the explanation for the observed effects.

\subsection{Bounded rationality}

In a rational expectations equilibrium, prices are efficient, reflecting the beliefs of market participants. However, if agent's beliefs are non-rational, that is, if market participants make consistently erroneous predictions, autocorrelated returns can result. One example of this approach to modelling is "bounded rationality" examined by Hussman (1992).

\footnotetext{
${ }^{6}$ See, e.g., Handa and Schwartz (1996) and Harris and Hasbrouck (1996).

${ }^{7} \mathrm{As}$ an example, it can be mentioned that the expected close-to-close return on holding the AFGX after a day of negative returns is negative, corresponding to an annualised yield of $-34 \%$ (sample period 1980-1995, results not reported). This is clearly not an equilibrium risk premium.

${ }^{8}$ Both these asset classes exhibit low, or negative, autocorrelation in daily and intraday returns. A similar observation is made by Boudoukh et al. (1994). For empirical support, see, e.g., Atchison et al. (1987) and the literature on lead-lag effects between index futures and cash index returns, for example, Chan (1992), Miller et al. (1994) and Abhyankar (1995, 1996).
} 
Agents are assumed to use simplified decision rules instead of the computationally difficult REE rules. In Hussman's model, agents use historical data to fit individual ARMA models of expected stock returns. When fundamentals change, agents will only be able to reestimate the parameter values of their ARMA specification gradually.

Hussman analyses the behaviour of asset prices close to a steady state where the fitted and actual ARMA processes are equal. As a result of the delayed learning of fundamentals, realised returns will be positively autocorrelated.

However, the short-term autocorrelation generated from this type of model is quite low. As time-varying risk premia, bounded rationality also requires that expected returns are relatively equal across asset classes. The model is clearly not compatible with observed levels of autocorrelation but may nevertheless contribute to aggregate levels of return autocorrelation. Bounded rationality is not considered in the empirical section as it is very difficult to test. ${ }^{9}$

\section{Empirical evidence}

\subsection{Some earlier empirical evidence on autocorrelation}

Table 1 provides a small selection of the rich earlier empirical evidence of index return autocorrelation. It is easily seen that index return autocorrelation is predominantly positive, regardless of data source or frequency. Positively autocorrelated index returns have prevailed for most of the twentieth century. There is some evidence of index return autocorrelation declining in recent years but there are no indications of autocorrelation disappearing altogether.

Of the stylised facts of autocorrelation, the small firm effect is the most prominent. Autocorrelation in portfolios of small stocks is significantly higher than for portfolios of large stocks. ${ }^{10}$

For the Swedish market, a few preceding studies exist. Nordén (1992) reports data on autocorrelation from the Stockholm Stock Exchange based on the OMX index. Similar to the findings in this paper, Nordén finds strong positive autocorrelation between Friday and Monday returns.

Nordén (1994) provides a study of Swedish intraday index returns, basically replicating the study of McInish and Wood (1991) using the Swedish OMx index. Although volatilities exhibit the standard U-shape, the results for autocorrelation are different. The highest autocorrelations are found in intraday-to-intraday returns.

In contrast to index return data, few examples of positive autocorrelation are to be found in empirical investigation of individual stock prices. Intraday returns are normally negatively autocorrelated due to bid-ask bounce.

Chan (1993) provides own-autocorrelation for size-sorted securities on the NYSE and AMEX. The reported average own stock autocorrelation ranges between -0.09 and 0.05 , and is clearly increasing in firm size. Berglund and Liljeblom (1988) report evidence of strong positive autocorrelation $(\approx 0.30)$ in daily stock returns of individual stocks on the Helsinki Stock Exchange. They also report

\footnotetext{
${ }^{9}$ Model selection is critical for both results and predictions. However, there is no clear economic rationale for choice of lag-lengths, return frequencies, ARMA-model, investor preferences etc.

${ }^{10}$ See, e.g., Lo and MacKinlay (1990b), Boudoukh et al. (1994) and McQueen et al. (1996).
} 
Table 1: Selected empirical evidence on index return autocorrelation

\begin{tabular}{|c|c|c|c|c|}
\hline Source & Series & $\begin{array}{l}\text { Sample } \\
\text { period }\end{array}$ & $\begin{array}{l}\text { Return } \\
\text { frequency }\end{array}$ & $\begin{array}{l}\text { First auto- } \\
\text { correlation }\end{array}$ \\
\hline \multirow[t]{3}{*}{ Campbell et al. (1993) } & $\mathrm{CRSP}^{v w}$ & $1950-62$ & daily & $0.13^{* *}$ \\
\hline & & $1962-74$ & daily & $0.28^{* *}$ \\
\hline & & $1975-87$ & daily & $0.17^{* *}$ \\
\hline \multirow[t]{3}{*}{ Atchison et al. (1987) } & $\mathrm{CRSP}^{e w}$ & $1978-81$ & daily & $0.17^{* *}$ \\
\hline & $\mathrm{CRSP}^{v w}$ & $1978-81$ & daily & $0.31^{* *}$ \\
\hline & Individual stocks & $1978-81$ & daily & 0.02 \\
\hline \multirow{2}{*}{$\begin{array}{l}\text { Lo and MacKinlay } \\
\text { (1990b) }\end{array}$} & $\mathrm{CRSP}^{e w_{\text {small stocks }}}$ & $1962-87$ & daily & $0.35^{* *}$ \\
\hline & $\mathrm{CRSP}^{e w}$ large stocks & $1962-87$ & daily & $0.17^{* *}$ \\
\hline \multirow{2}{*}{$\begin{array}{l}\text { Berglund and Liljeblom } \\
\text { (1988) }\end{array}$} & Helsinki $v w$ & $1977-82$ & daily & $0.49^{* *}$ \\
\hline & Individual stocks & $1977-82$ & daily & $\approx 0.30^{* *}$ \\
\hline \multirow[t]{3}{*}{ McInish and Wood (1991) } & NYSE ${ }^{e w}$ open & $1984-85$ & daily & $0.15^{*}$ \\
\hline & NYSE ${ }^{e w}$ midday & $1984-85$ & daily & 0.06 \\
\hline & $\mathrm{NYSE}^{e w}$ close & $1984-85$ & daily & $0.27^{* *}$ \\
\hline $\begin{array}{l}\text { Sentana and Wadhwani } \\
(1992)\end{array}$ & us index data & $1885-1988$ & daily & $0.11^{* *}$ \\
\hline \multirow[t]{2}{*}{ Chan (1993) } & small NYSE stocks & $1980-89$ & daily & $-0.09^{* *}$ \\
\hline & large NYSE stocks & $1980-89$ & daily & $0.05^{* *}$ \\
\hline Abhyankar (1995) & FT-SE 100 & $1986-90$ & $60 \mathrm{~min}$. & $0.14^{* *}$ \\
\hline \multirow[t]{2}{*}{ Chan et al. (1991) } & S\&P 500 & $1984-85$ & 5 min. & $0.45^{* *}$ \\
\hline & S\&P 500 & $1988-89$ & 5 min. & $0.27^{* *}$ \\
\hline \multirow[t]{2}{*}{ Stoll and Whaley (1990) } & S\&P 500 & $1982-87$ & 5 min. & $0.51^{* *}$ \\
\hline & мMI & $1984-86$ & 5 min. & $0.24^{* *}$ \\
\hline Abhyankar (1996) & FT-SE 100 & 1992 & 5 min. & $0.48^{* *}$ \\
\hline Chan (1992) & ммІ & $1984-85$ & 5 min. & $0.31^{* *}$ \\
\hline Nordén (1994) & OMx & $1991-93$ & 5 min. & $0.10^{* *}$ \\
\hline
\end{tabular}

Estimates and significance levels as reported in cited articles. Where significance levels were not reported, they were calculated using asymptotic standard errors. ${ }^{e w}$ Equally weighted index. $v w_{\text {Value-weighted index. }}^{* *} /{ }^{*} /{ }^{\circ}$ Significantly different from zero at the $0.01 / 0.05 /$ 0.10 level. 
that autocorrelation in individual stock returns is increasing (although not significantly) in the trading frequency. Berglund and Liljeblom (1990) also show that average autocorrelation in individual stock returns was lower $(0.05-0.11)$ in the high-volume years 1986-88 than in the low-volume years 1978-80 (0.30).

\subsection{Data}

The empirical tests use the following, comprehensive sample of return data from the Stockholm Stock Exchange. All data series are collected by Findata.

- Daily closing returns and trading volume on Affärsvärldens Generalindex (AFGX). The AFGX is a value-weighted stock market index covering all stocks traded on the Stockholm Stock Exchange. The index is calculated daily from the last recorded ask price of each stock. The index is not corrected for dividends. The sample period is 1980-1995, sixteen years with a total of 3998 observations.

- Daily closing returns of the OMx index, a narrow base index covering the 30 most traded stocks on the Stockholm Stock Exchange. This index is less affected by nontrading than the AFGX. Calculation of the OMX started in 1984.

- Closing returns and daily trading volume for 62 major stocks traded on the Stockholm Stock Exchange. The stocks were selected from all traded stocks based on sample length (more than ten years) and trading volume (highest), including all listed share classes of each company.

- Two indices created from the closing prices of the 62 stock series, one equally weighted $\left(\operatorname{SSE}^{e w}\right)$ and one value-weighted $\left(\operatorname{SSE}^{v w}\right)$.

\subsection{Methodology}

The returns are calculated using logarithmic differences of price (index) series. For individual stock series, returns are corrected for dividends:

$$
r_{i, t}=\log \left(\frac{P_{i, t}+D_{i, t}}{P_{i, t-1}}\right),
$$

where $D_{i, t}$ is positive only on ex-dividend days.

All regressions use least squares estimation. Standard errors are calculated using the GMM estimator of Hansen (1982), which is robust to both heteroskedasticity and, for the estimation of longer period returns, overlapping observations.

The reviewed theoretical models of return autocorrelation are limited to explaining return behaviour under "normal" circumstances. Therefore, it is natural to exclude observations from highly volatile periods. The only practical way to eliminate outliers in the large number of series studied here is to apply a mechanical rule. In all estimations, observations outside the central $95 \%$ of the return distribution are defined as outliers and excluded. The number of excluded observations for this reason is always close to $5 \%{ }^{11}$

\footnotetext{
${ }^{11}$ Inclusion of outliers increases the estimated standard error of estimates, but only marginally affects point estimates.
} 
The reported autocorrelations are all from regressions of the type

$$
r_{i, t}=\beta_{0}+\beta_{1} r_{i, t-1}+\varepsilon_{i, t} .
$$

The estimates of $\beta_{0}$ are always close to zero and are therefore not reported. Cross-autocorrelation with the market return is defined from regressions of the type

$$
r_{i, t}=\beta_{0}+\beta_{1} r_{m, t-1}+\varepsilon_{i, t} .
$$

Throughout this paper the AFGX index return is used as the market return. ${ }^{12}$

\subsection{Results}

\subsubsection{First and second autocorrelation of stock returns}

We start by examining the first and second autocorrelation of daily index returns. The results of table 2 show that stock index returns on the Stockholm Stock Exchange are strongly positively autocorrelated. The second autocorrelation is not statistically significant for any of the index series in the sample. Although not reported, there are no signs of any consistent higher order return autocorrelation.

As expected from the high liquidity of component stocks, the OMX index has the lowest autocorrelation of the studied index series. The autocorrelation of the calculated indices SSE ${ }^{e w}$ and $\mathrm{SSE}^{v w}$ is significantly higher than the autocorrelation of the AFGX index. The probable reason for this difference is that, for the AFGX, only the most liquid stock series of each company is used for the index calculation. In addition, the AFGX uses closing bid quotes, while the calculated indices are based on the last recorded transaction price. The autocorrelation in 11 industry indices included in the AFGX ranges between 0.132 and 0.271 (not reported). The AFGX index thus has higher autocorrelation than all component indices (0.296).

When the same test is repeated for individual stock returns, an interesting pattern is revealed with regard to trading volume (data in table 6 , page 22 $23)$. The average autocorrelation across all 62 securities is significantly positive (0.114). Individual estimates are significantly positive for more than half of the securities. As for indices, there are no signs of systematic higher order autocorrelation.

Figure $1 a$ provides a scatter plot of the estimated autocorrelation against the stocks' average daily trading volume. It is evident that the autocorrelation is increasing in the stocks' trading volume. The natural interpretation of figure $1 a$ is that stock returns are, in general, positively autocorrelated, but that bid-ask bounce reduces the measured autocorrelation for less liquid securities. Autocorrelation in individual stock returns is thus surprisingly close to the autocorrelation in index returns.

The similarity of autocorrelation in individual stock returns and index returns, indicates the likelihood of a common source to this autocorrelation. Among the sources of autocorrelation discussed in this paper, only profit taking, combined with imperfectly competitive markets, can generate this pattern of short-term autocorrelation in both individual stock returns and index returns.

\footnotetext{
${ }^{12}$ Different choices of market return only marginally affect regression results .
} 
Table 2: First and second autocorrelation of stock returns

\begin{tabular}{lcccc}
\hline & $\hat{\beta}_{1}$ & $\hat{\beta}_{2}$ & $R^{2}$ & $T$ \\
\hline \multirow{2}{*}{ Stocks $^{\dagger}$} & $0.114^{* *}$ & -0.004 & 0.012 & 2088 \\
& $(0.074)$ & $(0.033)$ & & 3483 \\
\multirow{2}{*}{ AFGX } & $0.296^{* *}$ & -0.000 & $0.056^{* *}$ & 2623 \\
\multirow{2}{*}{ OMX } & $(0.023)$ & $(0.025)$ & & 3473 \\
\multirow{2}{*}{ SSE } & $0.194^{* *}$ & 0.007 & $0.025^{* *}$ & \\
\multirow{2}{*}{ SSE } & $(0.028)$ & $(0.029)$ & & $0.094^{* *}$ \\
& $0.386^{* *}$ & -0.003 & & 3473 \\
& $(0.025)$ & $(0.028)$ & $0.067^{* *}$ & \\
\hline
\end{tabular}

Model used: $r_{t}=\beta_{0}+\beta_{1} r_{t-1}+\beta_{2} r_{t-2}+\varepsilon_{t}$. Regressions use least squares estimation with asymptotic GMM standard errors (in parentheses) that are robust to heteroskedasticity (Hansen, 1982). ${ }^{\dagger}$ Average of 62 individual estimates. Reported significance levels tests whether the mean is different from zero using the sample standard deviation (in parentheses). $* * / * /{ }^{\circ}$ Significantly different from zero at the $0.01 / 0.05 / 0.10$ level.

\subsubsection{Cross-autocorrelation with the market return}

Having established that Swedish index returns are positively autocorrelated, it follows that individual stock returns will exhibit strong cross-autocorrelation with the market return (Lo and MacKinlay, 1990b). However, it is not clear whether all stocks are as strongly cross-autocorrelated.

Figure $1 b$ plots autocorrelation and cross-autocorrelation with the AFGX against average trading volume (data in table 6, page 22-23). It is clear that, on average, the coefficient of cross-autocorrelation is higher $(0.385)$ than the coefficient of autocorrelation (0.114). The most traded securities exhibit significantly lower cross-autocorrelation with the market return. This is consistent with several models of lagging adjustment to common factors, and most probably reflects the lower nonsynchronicity of the prices of the most liquid stocks. As in figure $1 a$, autocorrelation in individual stock returns is increasing in average daily trading volume. ${ }^{13}$

\subsubsection{Autocorrelation conditional on past returns}

Table 3, panel $a$, presents autocorrelation conditional on the realised return on the preceding day (i.e., day $t-1$ ). This test is mainly exploratory and is aimed at investigating any asymmetry in return autocorrelation. Results show that autocorrelation is non-symmetric; positive following positive returns, but close to zero following negative returns. The results are similar for both individual stock returns and index returns. A similar asymmetry is documented by Sentana and Wadhwani (1992) for Us data and by Säfvenblad (1997b) for French data. ${ }^{14}$

\footnotetext{
${ }^{13}$ The lower point estimates follow from the multicollinearity between index returns and individual stock returns, in combination with the relative noisiness of individual stock returns.

${ }^{14} \mathrm{~A}$ check of a number of foreign index series in the Findata database reveals similar patterns of asymmetric autocorrelation for index series from a number of countries, including Denmark, Norway, Finland, Germany, Japan and Italy, but excluding Great Britain and the Us. Further work on the issue would be interesting, but is outside the scope of this paper.
} 
Figure 1: Scatter plot of autocorrelation and cross-autocorrelation with the market return against average daily trading volume

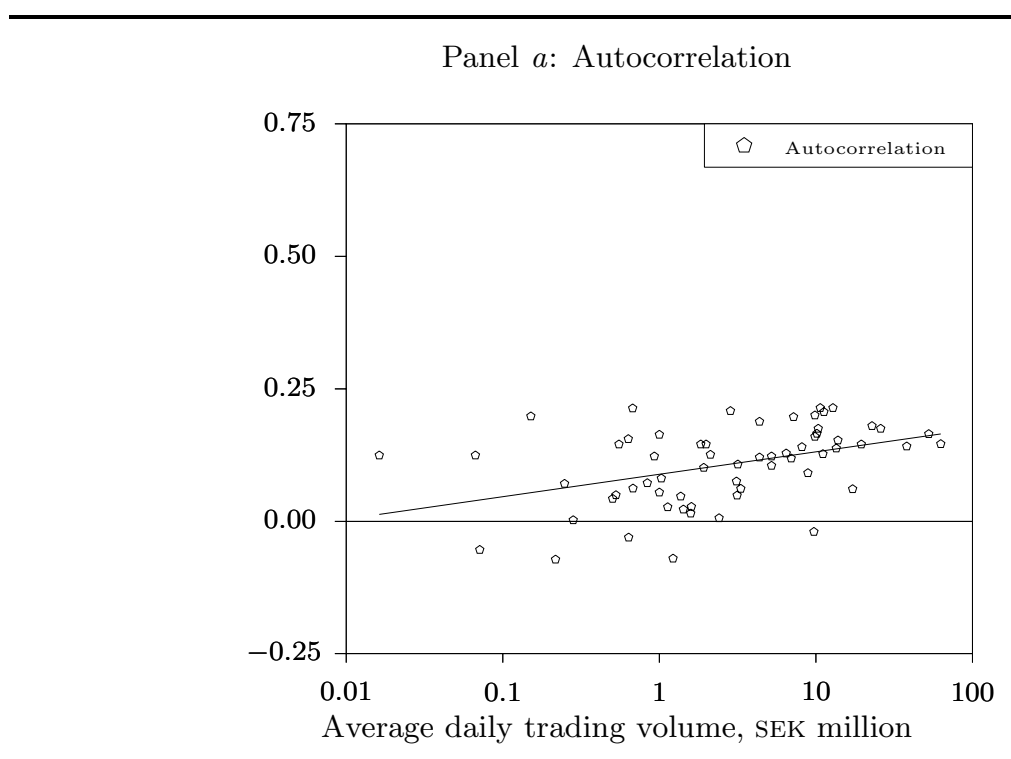

Panel $b$ : Autocorrelation and cross-autocorrelation with the market return

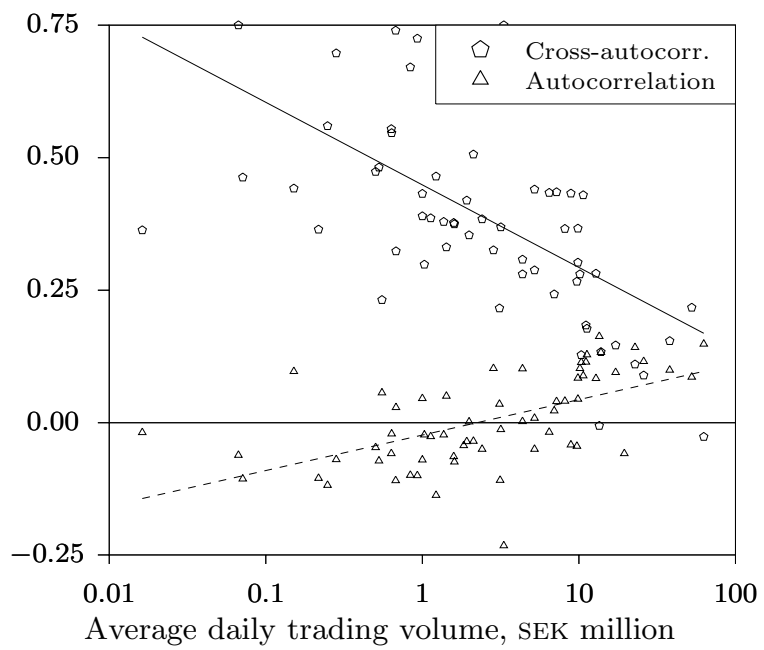

Panel $a$ regression model: $r_{t}=\beta_{0}+\beta_{1} r_{t-1}+\varepsilon_{t}$. Panel $b$ regression model: $r_{t}=\beta_{0}+$ $\beta_{1} r_{m, t-1}+\beta_{2} r_{i, t-1}+\varepsilon_{t}$. The individual point estimates are reported in table 6 . The lines are fitted least squares regression lines. The autocorrelation and volume data is taken from table 6. All slope coefficients are significantly different from zero (not reported). 
In relation to the surveyed autocorrelation models, this result is only consistent with profit taking under a short selling constraint in a non-competitive market, as modelled by Sentana and Wadhwani (1992), requiring, in addition, loss aversion of the kind hypothesised by Kahneman and Tversky (1979). This may be part of a more fundamental return property.

\subsubsection{Autocorrelation conditional on absolute returns}

Chan (1993) predicts higher return autocorrelation after days of high absolute market returns. The intuition behind this claim is that high absolute returns give a higher signal-to-noise ratio in prices. Agents will therefore give higher weight to previous price changes when updating their private valuation. Chan also presents empirical evidence from the NYSE supporting this prediction.

However, Chan's prediction is only valid if the returns are realised at the closing. If the high market returns are realised during the trading day, all information will be efficiently included in closing prices. As index returns are predicted to follow an MA(1)-process, higher volatility during the trading day will increase the variance of returns while keeping the autocovariance constant, resulting in a reduced estimate of autocorrelation.

Campbell et al. (1993) make the opposite prediction. In periods of high volatility, autocorrelation should be lower as the aggregate level of risk aversion is known with higher precision.

Table 3, panel $b$, presents a test of the proposition, conditioning autocorrelation on absolute realised returns. ${ }^{15}$ The results show that autocorrelation is lower conditional on high absolute returns. Results are similar both for index returns and individual stock returns. Most probably, this should be interpreted as support for the type of $\mathrm{MA}(1)$-process discussed above.

\subsubsection{Autocorrelation conditional on trading volume}

Explanations of index return autocorrelation based on information extraction predict lower autocorrelation after days of high trading volume. The improved price precision at the closing close reduces the scope for information extraction from the closing prices. The same prediction is also made by the nonsynchronous trading hypothesis. High trading volume reduces the nonsynchronicity of prices and resulting index return autocorrelation. The prediction is strongly supported by the results in table 3, panel $c$. Autocorrelation after high volume days is significantly lower for all investigated index series.

For individual stocks, the improved price precision should have similar effects. However, this is not the case. On the contrary, autocorrelation is significantly stronger after days of high trading volume. During the sample period, high volume days are often high return days. Therefore, it seems intuitive to attribute this autocorrelation to profit taking. The results in table 3 , panel $c$, can be seen as a time series test of the results presented in section 3.4.1 and figures $1 a-1 b$. The results are the same: autocorrelation increases conditional on increased trading volume.

\footnotetext{
${ }^{15}$ Conditioning on absolute returns is similar to conditioning on volatility. However, when other measures (ARCH/GARCH, centred estimates) are used, this effect of volatility on autocorrelation is very weak or non-existent (not reported).
} 
Table 3: Autocorrelation and cross-autocorrelation conditional on preceding day's return, trading volume and day-of-the-week

\begin{tabular}{|c|c|c|c|}
\hline & $\begin{array}{l}\hat{\beta}_{1} \\
\text { low }\end{array}$ & $\begin{array}{c}\hat{\beta}_{2} \\
h i g h\end{array}$ & Wald \\
\hline \multicolumn{4}{|c|}{ Panel $a$ : Fractiles of returns, $r_{i, t-1}$. } \\
\hline Stocks $^{\dagger}$ & $-0.021^{\circ}$ & $0.125^{* *}$ & $61.3^{* *}$ \\
\hline Cross-autocorrelation $^{\dagger \ddagger}$ & $0.258^{* *}$ & $0.421^{* *}$ & $11.3^{* *}$ \\
\hline AFGX & 0.063 & $0.308^{* *}$ & $4.8^{*}$ \\
\hline OMX & 0.030 & $0.254^{* *}$ & $4.5^{*}$ \\
\hline $\operatorname{sSE}^{v w}$ & $0.168^{*}$ & $0.349^{* *}$ & $3.4^{\circ}$ \\
\hline $\operatorname{SSE}^{e w}$ & $0.180^{*}$ & $0.342^{* *}$ & $2.8^{\circ}$ \\
\hline \multicolumn{4}{|c|}{ Panel $b$ : Fractiles of absolute returns, $\left|r_{i, t-1}\right|$. } \\
\hline Stocks $^{\dagger}$ & $0.164^{* *}$ & $0.047^{* *}$ & $50.0^{* *}$ \\
\hline Cross-autocorrelation $^{\dagger \ddagger}$ & $0.504^{* *}$ & $0.328^{* *}$ & $17.2^{* *}$ \\
\hline AFGX & $0.368^{* *}$ & $0.175^{* *}$ & $7.0^{* *}$ \\
\hline OMX & $0.320^{* *}$ & $0.132^{* *}$ & $5.2^{*}$ \\
\hline $\mathrm{SSE}^{v w}$ & $0.391^{* *}$ & $0.259^{* *}$ & $3.4^{\circ}$ \\
\hline $\operatorname{SSE}^{e w}$ & $0.401^{* *}$ & $0.261^{* *}$ & $3.4^{\circ}$ \\
\hline \multicolumn{4}{|c|}{ Panel $c$ : Fractiles of trading volume, $V_{i, t-1}$. } \\
\hline Stocks $^{\dagger}$ & $0.084^{* *}$ & $0.120^{* *}$ & $4.8^{*}$ \\
\hline Cross-autocorrelation $^{\dagger \ddagger}$ & $0.651^{* *}$ & $0.373^{* *}$ & $24.0^{* *}$ \\
\hline AFGX & $0.374^{* *}$ & $0.199^{* *}$ & $12.7^{* *}$ \\
\hline OMX & $0.312^{* *}$ & $0.121^{* *}$ & $11.5^{* *}$ \\
\hline $\operatorname{sSE}^{v w}$ & $0.458^{* *}$ & $0.330^{* *}$ & $8.0^{* *}$ \\
\hline $\operatorname{SSE}^{e w}$ & $0.461^{* *}$ & $0.325^{* *}$ & $9.2^{* *}$ \\
\hline Panel $d$ : Day-of-the-week & Mon.-Thu. & Fri. & \\
\hline Stocks $^{\dagger}$ & $0.038^{* *}$ & $0.123^{* *}$ & $28.1^{* *}$ \\
\hline Cross-autocorrelation $^{\dagger \ddagger}$ & $0.291^{* *}$ & $0.553^{* *}$ & $36.0^{* *}$ \\
\hline AFGX & $0.143^{* *}$ & $0.380^{* *}$ & $9.0^{* *}$ \\
\hline OMX & $0.098^{* *}$ & $0.339^{* *}$ & $8.1^{* *}$ \\
\hline $\operatorname{SSE}^{v w}$ & $0.222^{* *}$ & $0.463^{* *}$ & $10.8^{* *}$ \\
\hline $\operatorname{SSE}^{e w}$ & $0.222^{* *}$ & $0.480^{* *}$ & $12.6^{* *}$ \\
\hline
\end{tabular}

Regression model: $r_{t}=\beta_{0}+\left(\beta_{1} D_{1, t-1}+\beta_{2} D_{2, t-1}\right) r_{t-1}+\varepsilon_{t}$. Panel $a, b$ and $c: D_{1, t}$ $\left(D_{2, t}\right)$ is a dummy variable for low (high) returns/absolute returns/trading volume. Panels $a$ and $b$ : Outliers not excluded. Panel $c$ : Trading volume uses logarithms of daily trading volume, detrended using a centred 100 trading day moving average. Panel $d: D_{1, t}\left(D_{2, t}\right)$ is a dummy variable for Monday-Thursday (Friday). Regressions use least squares estimation with asymptotic GMM standard errors (not reported) that are robust to heteroskedasticity (Hansen, 1982). The Wald statistic tests the restriction $\beta_{1}=\beta_{2} \cdot \chi^{2}(1)$ critical values: 6.6/ $3.8 / 2.7$ at the $0.01 / 0.05 / 0.10$ level. ${ }^{\dagger}$ Average of 62 individual estimates. Reported significance levels tests whether the mean is different from zero using the sample standard deviation (not reported). ${ }^{\ddagger}$ Cross-autocorrelation with the AFGX. ${ }^{* *} / * / 0$ Significantly different from zero at the $0.01 / 0.05 / 0.10$ level. 
Table 4: Return autocorrelation conditional on the level of transaction tax

\begin{tabular}{lcccccc}
\hline & $\hat{\beta}_{1}$ & $\hat{\beta}_{2}$ & $\hat{\beta}_{3}$ & $\hat{\beta}_{4}$ & $\hat{\beta}_{5}$ & \\
Series & $0.0 \%$ & $0.5 \%$ & $1.0 \%$ & $0.5 \%$ & $0.0 \%$ & Wald \\
\hline Stocks $^{\dagger}$ & $0.117^{* *}$ & $0.078^{* *}$ & $0.124^{* *}$ & $0.071^{* *}$ & $0.069^{* *}$ & 7.4 \\
Cross-auto- $^{\dagger *}$ & $0.324^{* *}$ & $0.564^{* *}$ & $0.549^{* *}$ & $0.619^{* *}$ & $0.284^{* *}$ & $44.8^{* *}$ \\
correlation & & & & & & \\
AFGX & & & & & \\
OMX & $0.382^{* *}$ & $0.286^{* *}$ & $0.263^{* *}$ & $0.397^{* *}$ & $0.169^{* *}$ & $15.9^{* *}$ \\
$\operatorname{SSE}^{v w}$ & $\ldots$ & $0.234^{* *}$ & $0.205^{* *}$ & $0.270^{* *}$ & $0.106^{*}$ & $57.7^{* *}$ \\
$\operatorname{SSE}^{e w}$ & $0.543^{* *}$ & $0.373^{* *}$ & $0.364^{* *}$ & $0.401^{* *}$ & $0.204^{* *}$ & $31.2^{* *}$ \\
\hline
\end{tabular}

Regression model: $r_{t}=\beta_{0}+\left(\beta_{1} D_{1, t-1}+\ldots+\beta_{5} D_{5, t-1}\right) r_{t-1}+\varepsilon_{t} . D_{1, t}, \ldots, D_{5, t}$ are dummies for the five different tax periods; 1) Jan. 1980 - Dec. 1983: no tax, 2) Jan. 1984 - Dec. 1985: 0.5\% (roundtrip), 3) Jan. 1986 - Dec. 1990: 1.0\%, 4) Jan. 1991 - Nov. 1992: 0.5\%, and, 5) Dec. 1992 - Dec. 1995: no tax. Regressions use least squares estimation with asymptotic GMM standard errors (not reported) that are robust to heteroskedasticity (Hansen, 1982). The Wald statistic tests the restriction $\beta_{1}=\ldots=\beta_{5} \cdot \chi^{2}(4)$ critical values: $13.2 / 9.4$ / 7.7 at the $0.01 / 0.05 / 0.10$ level. ${ }^{\dagger}$ Average of 62 individual estimates. Reported significance levels tests whether the mean is different from zero using the sample standard deviation (not reported). ${ }^{\ddagger}$ Cross-autocorrelation with the AFGX. ${ }^{* *} / * /{ }^{\circ}$ Significantly different from zero at the $0.01 / 0.05 / 0.10$ level.

\subsubsection{Day-of-the-week effects}

Table 3, panel $d$, presents autocorrelation conditional on day-of-the-week. Autocorrelation is significantly higher between Monday and Friday returns both for index returns and individual stock returns. ${ }^{16}$ The results further strengthen the conclusion that the same factors drive autocorrelation in index returns and individual stock returns. In particular, the results strengthen the case for profit taking. It is reasonable to believe that profit takers are most eager to close their positions at Friday afternoon, when they risk a weekend of nontrading and possible losses.

\subsubsection{Autocorrelation and the Swedish stock market transaction tax}

During the period 1984-92, Sweden levied a transaction tax on all stock market transactions, which made short-term speculation in Swedish stocks very costly. This is thus a very direct testing ground for the transaction cost hypothesis that transaction costs increase observed index return autocorrelation.

The introduction, changes, and abolition of the turnover tax divide the sample period into five distinct subperiods: three separate tax regimes and two periods without transaction tax. The results given in table 4 provide some support for the predictions of the transaction cost hypothesis. Autocorrelation dropped significantly when the transaction tax was abolished. However, it also decreased when the transaction tax was first introduced. It is therefore impossible to draw any firm conclusions based on this evidence.

Cross-autocorrelation with the market return clearly increased during the transaction tax period. Using the cross-security information aggregation model

\footnotetext{
${ }^{16}$ Boudoukh et al. (1994) also find the strongest index return autocorrelation between Friday and Monday returns (us data).
} 
Table 5: First order autocorrelation in $N$-day returns

\begin{tabular}{|c|c|c|c|c|c|c|}
\hline$N$ & Stocks $^{\dagger}$ & $\begin{array}{l}\text { Cross-auto- } \\
\text { correlation }^{\dagger \ddagger}\end{array}$ & AFGX & OMX & $\mathrm{SSE}^{v w}$ & $\mathrm{SSE}^{e w}$ \\
\hline 1 & $0.106^{* *}$ & $0.456^{* *}$ & $0.290^{* *}$ & $0.193^{* *}$ & $0.393^{* *}$ & $0.391^{* *}$ \\
\hline 2 & $0.069^{* *}$ & $0.279^{* *}$ & $0.165^{* *}$ & $0.127^{* *}$ & $0.251^{* *}$ & $0.270^{* *}$ \\
\hline 3 & $0.055^{* *}$ & $0.224^{* *}$ & $0.134^{* *}$ & $0.102^{* *}$ & $0.184^{* *}$ & $0.183^{* *}$ \\
\hline 4 & $0.063^{* *}$ & $0.244^{* *}$ & $0.147^{* *}$ & $0.106^{* *}$ & $0.197^{* *}$ & $0.203^{* *}$ \\
\hline 5 & $0.061^{* *}$ & $0.229^{* *}$ & $0.135^{* *}$ & $0.085^{*}$ & $0.174^{* *}$ & $0.180^{* *}$ \\
\hline 10 & $0.071^{* *}$ & $0.300^{* *}$ & $0.195^{* *}$ & $0.136^{*}$ & $0.228^{* *}$ & $0.238^{* *}$ \\
\hline 20 & $0.063^{* *}$ & $0.226^{* *}$ & $0.140^{\circ}$ & 0.124 & $0.219^{* *}$ & $0.232^{* *}$ \\
\hline 30 & $0.051^{* *}$ & $0.133^{* *}$ & 0.121 & 0.079 & $0.209^{\circ}$ & $0.214^{\circ}$ \\
\hline 40 & $0.067^{* *}$ & $0.192^{* *}$ & 0.162 & 0.047 & $0.250^{\circ}$ & $0.253^{\circ}$ \\
\hline 60 & $0.070^{* *}$ & $0.248^{* *}$ & 0.224 & -0.005 & $0.329^{*}$ & $0.334^{*}$ \\
\hline
\end{tabular}

Regression model: $P_{t}-P_{t-N}=\beta_{0}+\beta_{1}\left(P_{t-N}-P_{t-2 N+1}\right)+\varepsilon_{t}$. Significance levels are calculated using GMM standard errors (not reported) that are robust to overlapping observations and heteroskedasticity (See Hansen (1982), Richardson and Smith (1994)) ${ }^{\dagger}$ Average of 62 individual estimates. Reported significance levels tests whether the mean is different from zero using the sample standard deviation (not reported). ${ }^{\ddagger}$ Cross-autocorrelation with the AFGX. $* * / * /{ }^{\circ}$ Significantly different from zero at the $0.01 / 0.05 / 0.10$ level.

of Säfvenblad (1997a), this is most likely due to reduced informativeness of individual stock prices relative to the informativeness of the index level. However, there is no direct way to test this hypothesis as it is impossible to measure the absolute level of stock price informativeness.

\subsubsection{First order autocorrelation of $N$-day returns}

Daily return series can be used to construct returns for longer holding periods. ${ }^{17}$ Table 5 reports autocorrelation estimates for different holding period lengths, ranging from one trading day to almost three months. Longer holding periods are not considered due to the limited sample length.

In addition to the earlier observed autocorrelation in daily returns, positive autocorrelation extends to holding periods of up to at least one month. Effects seem to be smaller for the more liquid stocks contained in the omx index. As in most earlier regressions, results are similar for stock index returns and individual stocks returns.

For the longer horizon returns, time-varying expected returns is the natural explanation, as results are similar for both individual stocks and stock indices. The expected (annualised) monthly return conditional on a down-month is approximately 12\%, compared with $23 \%$ conditional on an up-month (not reported). However, time-varying expected returns cannot be used to explain the observed autocorrelation in daily and weekly returns. Furthermore, as discussed earlier, the short-term autocorrelation is too high to be explained by nonsynchronous trading. Judging from earlier regressions, profit taking seems to best explain the remaining autocorrelation in short-term returns.

Although it is important to interpret the significance levels of these results

\footnotetext{
${ }^{17}$ The $N$-day returns are constructed by taking log differences of the price or index level $N$ trading days apart.
} 
with care, ${ }^{18}$ it is evident from table 5 that there is no negative autocorrelation or price reversals in returns, regardless of return frequency.

\subsubsection{Stability of autocorrelation estimates}

An interesting diagnostic test is whether the estimated coefficients of autocorrelations are stable over time. Exact estimates are not reported, but figure 2 shows the estimated time variation of autocorrelation (solid lines). It is evident from figures $2 a$ and $b$ that index return autocorrelation has been consistently positive throughout the sample period.

For autocorrelation in individual stock returns, striking patterns of changes can be seen over time (figures $2 c-d$ ). For the most liquid securities, autocorrelation increased in the last years of the sample period. The best explanation for this pattern is increased profit taking, in the sense that profit taking takes place nearer to the closing, and not earlier during the trading day. This may be a result of improved liquidity during the last trading hour.

For the least liquid securities, autocorrelation has consistently decreased, and is strongly negative at the end of the sample period. This implies increased transaction costs for the less liquid securities or, simply, more noise trading at the closing.

\subsubsection{Nonsynchronous trading}

Nonsynchronous trading is a relatively important problem in the sample, in particular for the calculated return series, $\mathrm{SSE}^{e w}$ and $\mathrm{SSE}^{v w}$. During the sample period, the daily nontrading frequency is approximately $15 \%$. However, during the last $2-3$ years of the sample period, daily nontrading is virtually nonexistent.

Figures $2 a$ and $b$ compare the time-varying autocorrelation in the OMX and the SSE $e w$ (solid line) to the autocorrelation predicted by the Lo and MacKinlay (1990a) nonsynchronous trading model (dotted line). It is evident that, especially for the early and late part of the sample period, nonsynchronous trading can only account for part of the observed autocorrelation.

\subsubsection{Non-linear dynamics}

Obviously, the relation between autocorrelation, return, and volume, can be non-linear. However, judging from a quadratic specification of returns, trading volume and autocorrelation, non-linearity is weak. The point estimates mostly confirm earlier findings and are therefore omitted. However, the point estimates can be used to illustrate how autocorrelation and expected returns depend on realised returns and trading volume.

Figure $3 a$ shows the autocorrelation pattern of the AFGX using parameter estimates from the quadratic model. It is clear that autocorrelation is highest conditional on low trading volume and high returns (the back right corner). The inverted U-shape along the $r_{t-1}$ axis shows the relatively weak volatility effect. Although trading volume reduces index return autocorrelation, the effect is not strong enough to eliminate the positive autocorrelation.

\footnotetext{
${ }^{18}$ The estimates of autocorrelation for different holding periods are highly correlated. See Richardson and Smith (1994).
} 
Figure 2: Time-varying autocorrelation in stock returns

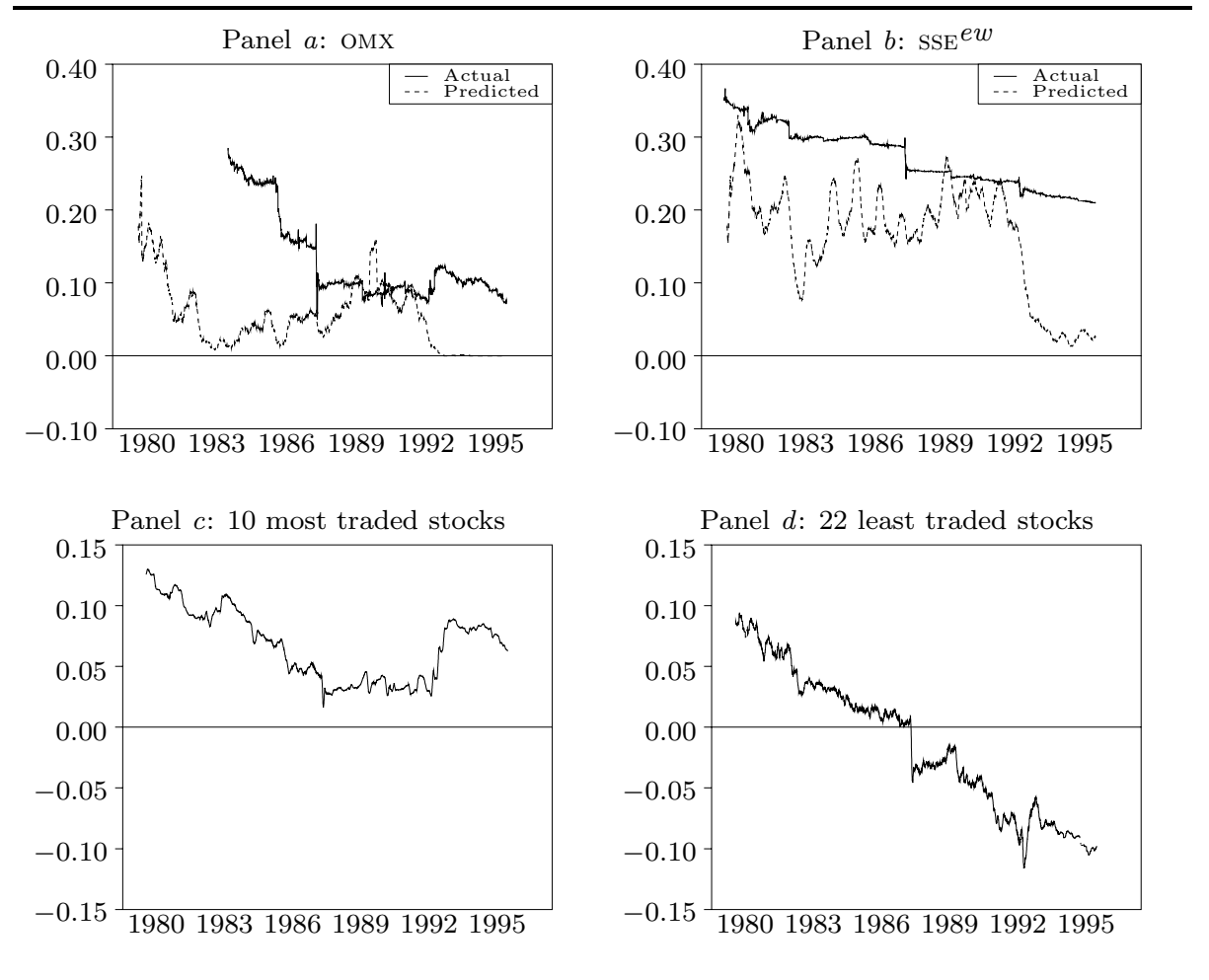

Panels $a$ and $b$ : Time-varying autocorrelation estimated using a standard Kalman filter with time-varying coefficients (solid line). Predicted autocorrelation using estimates of nontrading and the model of Lo and MacKinlay (1990a) (dotted line). Panel $a$ : Nontrading estimated from the 20 most traded stocks in the sample. Panel $b$ : Actual nontrading. Panel $c$ and $d$ : Average autocorrelation in individual stock returns across the 10 most/22 least traded stocks in the sample. 
Figure 3: Autocorrelation and expected returns of daily AFGX returns conditional on the preceding day's return and trading volume

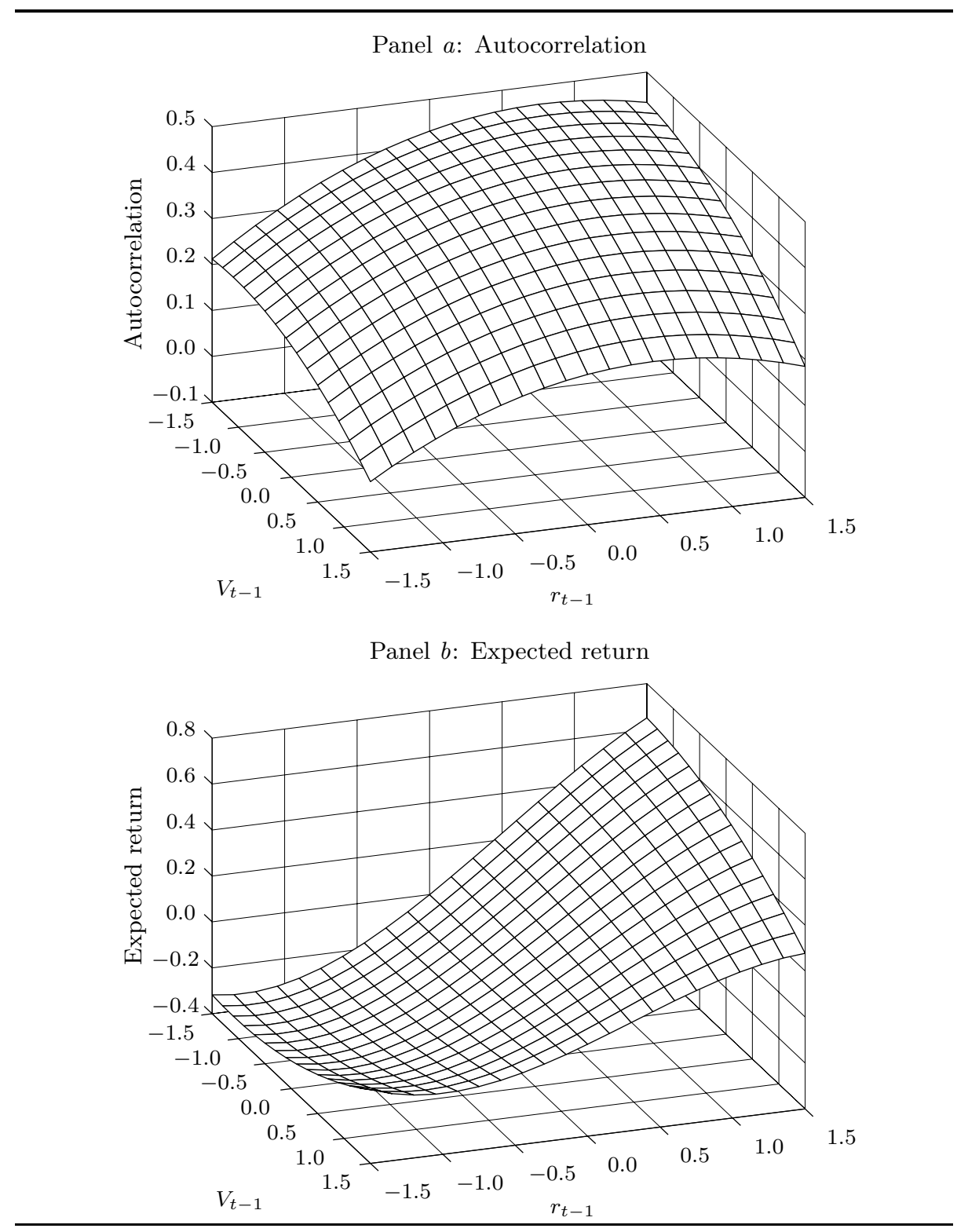

Panel $a$ : The fitted values of AFGX autocorrelation plotted as a function of preceding day's trading volume and return. Panel $b$ : The expected AFGX returns plotted as a function of preceding day's trading volume and return. Panels $a$ and $b$ : Volume and returns are normalised to have zero mean and standard deviation 1. 
In figure $3 b$ the corresponding expected returns are plotted. Here the asymmetry between high (right edge) and low returns (left edge) is highly visible. There is a strong volume effect conditional on high returns (right edge), while after low returns, trading volume does not seem to matter. If returns are strongly negative, lower returns do not seem to decrease expected returns any further. There is thus minimum possible expected return.

\section{Conclusion}

This paper is primarily an exploratory investigation into the autocorrelation structure of Swedish stock index returns. In spite of the modest mission statement, the paper provides a number of interesting results. The most important finding is the similarity between autocorrelation in individual stock returns and stock index returns.

Autocorrelation is much stronger in index returns, but autocorrelation in index returns and individual stock returns exhibit many common properties, including return dependence, volatility dependence and day-of-the-week dependence. Therefore, it is natural to conclude that common factors drive autocorrelation in both index returns and individual stock returns. The exception to the similarity is the trading volume dependence, where trading volume reduces index return autocorrelation while it increases autocorrelation in individual stock returns.

Clearly, nonsynchronous trading contributes to the measured level of index return autocorrelation. However, it cannot account for all observed return autocorrelation, particularly not in the last years of the sample period. Nontrading probabilities have been significantly reduced, but index return autocorrelation remains high.

For individual stocks, it is clear that high trading volume increases autocorrelation, both when estimated cross-sectionally and when estimated using time series methods. This effect is most probably due to stronger bid-ask bounce effects for the less liquid securities, and on less active trading days. If this is true, individual stock returns are in general positively autocorrelated. Of the reviewed theoretical models, this is only consistent with profit taking in a non-competitive market.

On average, autocorrelation in individual stock returns has remained more or less constant during the sample period. However, while autocorrelation in the most liquid stocks has remained constant or increased, autocorrelation in the least liquid stocks has decreased steadily throughout the sample period. In the later parts of the sample period, autocorrelation is significantly positive for the most liquid stocks while it is significantly negative for the least liquid stocks.

One very interesting result is the asymmetry of autocorrelation. Conditional on high realised returns, index return autocorrelation is strongly positive, while, conditional on negative returns, autocorrelation is close to zero. The documented asymmetry in return autocorrelation is present in both index returns and individual stock returns. This supports the hypothesis of profit taking. Profit taking is also supported by the strong autocorrelation between Friday and Monday returns. The effect, visible in both index and individual stock returns, may be caused by particularly strong profit taking before the weekend. 
The Swedish stock market transaction tax provided a direct test of the transaction cost hypothesis. Although transaction costs had only small effects on index return autocorrelation, they seem to have reduced price informativeness. This was concluded from the increased cross-autocorrelation with the market return.

For longer term returns, time-varying expected returns provide a good explanation of the data. This is mainly a passive conclusion, since it is the only theoretical model of return autocorrelation that fits the data. However, some explicit support is given by the similarity of individual stock returns and index returns.

From the collected empirical evidence, it can be concluded that autocorrelation in short-term returns is best described as a combination of profit taking and nonsynchronous trading (for index returns). This conclusion is primarily based on the observation that autocorrelation in index returns and individual stocks have similar properties in terms of return dependence, day-of-the-week dependence and volatility dependence. Further support for the profit taking hypothesis is given by the strong positive autocorrelation in the most liquid securities. Future studies, using intraday price data, will be needed to evaluate whether this is a correct interpretation of the data. 
Table 6: First and second autocorrelation and cross-autocorrelation with market return

\begin{tabular}{|c|c|c|c|c|c|c|}
\hline \multirow[b]{2}{*}{ Name } & \multicolumn{2}{|c|}{ Regression 1} & \multicolumn{2}{|c|}{ Regression 2} & \multirow[b]{2}{*}{ Volume $^{\dagger}$} & \multirow[b]{2}{*}{$T$} \\
\hline & $\hat{\beta}_{1}$ & $\hat{\beta}_{2}$ & $\hat{\beta}_{1}$ & $\hat{\beta}_{2}$ & & \\
\hline Ericsson $\mathrm{B}$ & $0.146^{* *}$ & 0.003 & -0.026 & $0.148^{* *}$ & 62.4 & 3998 \\
\hline Astra A & $0.168^{* *}$ & 0.005 & $0.217^{* *}$ & $0.086^{* *}$ & 52.3 & 3267 \\
\hline Volvo B & $0.147^{* *}$ & 0.010 & $0.154^{* *}$ & $0.099^{* *}$ & 37.9 & 3998 \\
\hline Astra B & $0.178^{* *}$ & -0.046 & 0.089 & $0.115^{* *}$ & 25.9 & 2144 \\
\hline Electrolux B & $0.178^{* *}$ & 0.023 & $0.110^{*}$ & $0.142^{* *}$ & 22.7 & 3998 \\
\hline Investor B & $0.139^{* *}$ & -0.016 & $0.616^{* *}$ & $-0.058^{\circ}$ & 19.4 & 2829 \\
\hline SE-banken A & $0.064^{\circ}$ & 0.067 & $0.146^{\circ}$ & 0.095 & 17.1 & 3998 \\
\hline Skandia & $0.153^{* *}$ & 0.016 & $0.133^{*}$ & $0.133^{* *}$ & 13.8 & 3998 \\
\hline Volvo BB & $0.135^{* *}$ & 0.002 & -0.006 & $0.163^{* *}$ & 13.4 & 3242 \\
\hline $\mathrm{ABB}$ в & $0.228^{* *}$ & -0.021 & $0.282^{* *}$ & $0.083^{* *}$ & 12.8 & 3168 \\
\hline Kinnevik B & $0.210^{* *}$ & 0.024 & $0.178^{*}$ & $0.128^{* *}$ & 11.2 & 1744 \\
\hline $\mathrm{SHB}$ A & $0.127^{* *}$ & -0.025 & $0.184^{* *}$ & $0.114^{*}$ & 11.0 & 3998 \\
\hline Stora B & $0.199^{* *}$ & 0.049 & $0.430^{* *}$ & $0.088^{*}$ & 10.6 & 1834 \\
\hline SKF B & $0.175^{* *}$ & 0.020 & $0.127^{*}$ & $0.114^{* *}$ & 10.3 & 3998 \\
\hline Atlas Copco B & $0.174^{* *}$ & 0.001 & $0.280^{* *}$ & $0.102^{*}$ & 10.1 & 1596 \\
\hline $\mathrm{ABB} A$ & $0.217^{* *}$ & -0.025 & $0.302^{* *}$ & $0.084^{* *}$ & 9.8 & 3998 \\
\hline Skanska B & $0.159^{* *}$ & 0.043 & $0.366^{* *}$ & 0.044 & 9.8 & 3005 \\
\hline Avesta & -0.022 & -0.028 & $0.266^{*}$ & -0.044 & 9.6 & 1817 \\
\hline SCA B & $0.101^{* *}$ & $-0.034^{\circ}$ & $0.433^{* *}$ & -0.042 & 8.8 & 3998 \\
\hline MoDo B & $0.152^{* *}$ & -0.000 & $0.366^{* *}$ & $0.041^{*}$ & 8.1 & 3998 \\
\hline Stora A & $0.205^{* *}$ & 0.005 & $0.435^{* *}$ & 0.040 & 7.2 & 3998 \\
\hline Atlas Copco A & $0.124^{* *}$ & -0.013 & $0.242^{* *}$ & 0.022 & 6.9 & 3998 \\
\hline Sandvik B & $0.145^{* *}$ & -0.024 & $0.434^{* *}$ & -0.018 & 6.4 & 3998 \\
\hline Sandvik A & $0.176^{* *}$ & -0.035 & $0.440^{* *}$ & -0.050 & 5.1 & 2509 \\
\hline H\&M в & $0.129^{* *}$ & -0.032 & $0.288^{* *}$ & 0.009 & 5.1 & 3998 \\
\hline Aga B & $0.118^{* *}$ & -0.015 & $0.308^{* *}$ & 0.002 & 4.3 & 3998 \\
\hline Skanska BB & $0.193^{* *}$ & 0.034 & $0.280^{* *}$ & $0.102^{* *}$ & 4.3 & 3242 \\
\hline Custos A & 0.060 & 0.012 & $0.764^{* *}$ & $-0.232^{\circ}$ & 3.3 & 1801 \\
\hline Volvo A & $0.116^{* *}$ & -0.034 & $0.369^{* *}$ & -0.013 & 3.1 & 3998 \\
\hline Investor A & $0.061^{\circ}$ & 0.012 & $0.706^{* *}$ & $-0.109^{* *}$ & 3.1 & 3998 \\
\hline Gambro B & $0.071^{*}$ & -0.000 & $0.216^{* *}$ & 0.035 & 3.1 & 3177 \\
\hline Stora AB & $0.202^{* *}$ & 0.022 & $0.325^{* *}$ & $0.103^{* *}$ & 2.8 & 3110 \\
\hline Nobel A & 0.008 & $-0.065^{*}$ & $0.384^{* *}$ & -0.050 & 2.4 & 3548 \\
\hline Industrivärden A & $0.127^{* *}$ & -0.030 & $0.506^{* *}$ & -0.035 & 2.1 & 3998 \\
\hline Sandvik AB & $0.166^{* *}$ & 0.011 & $0.354^{* *}$ & 0.002 & 1.9 & 3108 \\
\hline
\end{tabular}

The table continues on the next page. 
Table 6 continued

\begin{tabular}{|c|c|c|c|c|c|c|}
\hline \multirow[b]{2}{*}{ Name } & \multicolumn{2}{|c|}{ Regression 1} & \multicolumn{2}{|c|}{ Regression 2} & \multirow[b]{2}{*}{ Volume $^{\dagger}$} & \multirow[b]{2}{*}{$T$} \\
\hline & $\hat{\beta}_{1}$ & $\hat{\beta}_{2}$ & $\hat{\beta}_{1}$ & $\hat{\beta}_{2}$ & & \\
\hline Volvo AB & $0.104^{* *}$ & -0.004 & $0.419^{* *}$ & -0.036 & 1.9 & 3242 \\
\hline Investor $\mathrm{AB}$ & $0.157^{* *}$ & 0.010 & $0.611^{* *}$ & -0.043 & 1.8 & 3242 \\
\hline SKF A & 0.010 & -0.045 & $0.375^{* *}$ & $-0.074^{\circ}$ & 1.5 & 3005 \\
\hline Aga A & 0.022 & 0.007 & $0.377^{* *}$ & -0.064 & 1.5 & 3005 \\
\hline SE-banken C & 0.012 & $-0.099^{*}$ & $0.331^{*}$ & 0.050 & 1.4 & 1653 \\
\hline Esselte B & 0.048 & 0.040 & $0.379^{* *}$ & -0.023 & 1.3 & 3998 \\
\hline Industrivärden C & $-0.076^{\circ}$ & -0.011 & $0.465^{* *}$ & $-0.137^{* *}$ & 1.2 & 1842 \\
\hline Avesta B & 0.028 & -0.026 & $0.386^{* *}$ & -0.026 & 1.1 & 1907 \\
\hline Gambro BB & $0.081^{*}$ & -0.002 & $0.298^{* *}$ & -0.023 & 1.0 & 2421 \\
\hline SKF BB & $0.161^{* *}$ & -0.003 & $0.390^{* *}$ & 0.046 & 1.0 & 2096 \\
\hline Hufvudstaden A & $0.051^{\circ}$ & -0.032 & $0.432^{* *}$ & -0.070 & 0.9 & 3998 \\
\hline Custos B & $0.132^{* *}$ & 0.025 & $0.725^{* *}$ & $-0.100^{\circ}$ & 0.9 & 3998 \\
\hline SCA A & $0.078^{*}$ & $-0.055^{*}$ & $0.671^{* *}$ & $-0.099^{* *}$ & 0.8 & 3005 \\
\hline Esselte $\mathrm{AB}$ & $0.065^{\circ}$ & 0.033 & $0.324^{* *}$ & 0.029 & 0.6 & 3117 \\
\hline Custos AB & $0.230^{* *}$ & 0.007 & $0.740^{* *}$ & -0.109 & 0.6 & 3242 \\
\hline Nobel B & -0.058 & $-0.051^{\circ}$ & $0.547^{* *}$ & -0.021 & 0.6 & 3114 \\
\hline SKF AB & $0.154^{* *}$ & 0.007 & $0.554^{* *}$ & -0.058 & 0.6 & 3089 \\
\hline Kinnevik A & $0.125^{*}$ & 0.048 & $0.232^{\circ}$ & 0.056 & 0.5 & 1293 \\
\hline Ratos A & $0.065^{\circ}$ & -0.042 & $0.482^{* *}$ & $-0.072^{\circ}$ & 0.5 & 3998 \\
\hline Bergman \& Bev. B & 0.042 & 0.029 & $0.473^{* *}$ & $-0.047^{\circ}$ & 0.5 & 3998 \\
\hline MoDo A & $0.097^{*}$ & 0.038 & $0.697^{* *}$ & $-0.070^{\circ}$ & 0.2 & 3998 \\
\hline Industrivärden B & 0.118 & 0.041 & $0.560^{* *}$ & $-0.118^{\circ}$ & 0.2 & 1195 \\
\hline Ericsson A & -0.054 & -0.026 & $0.365^{* *}$ & $-0.105^{* *}$ & 0.2 & 3998 \\
\hline Kinnevik BB & $0.209^{* *}$ & -0.020 & $0.442^{* *}$ & $0.097^{* *}$ & 0.1 & 3042 \\
\hline Ericsson $\mathrm{AB}$ & 0.008 & 0.013 & $0.463^{* *}$ & $-0.106^{*}$ & 0.0 & 3242 \\
\hline Industrivärden $\mathrm{CB}$ & 0.199 & -0.056 & $1.060^{\circ}$ & -0.062 & 0.0 & 335 \\
\hline Kinnevik AB & $0.135^{\circ}$ & 0.043 & $0.363^{\circ}$ & -0.018 & 0.0 & 3042 \\
\hline Average $^{\ddagger}$ & $0.114^{* *}$ & -0.004 & $0.385^{* *}$ & 0.004 & 7.4 & 3149 \\
\hline Standard error & $(0.074)$ & $(0.033)$ & $(0.197)$ & $(0.086)$ & & \\
\hline
\end{tabular}

Regression models: $r_{t}=\beta_{0}+\beta_{1} r_{t-1}+\beta_{2} r_{t-2}+\varepsilon_{t}$ and $r_{t}=\beta_{0}+\beta_{1} r_{m, t-1}+\beta_{2} r_{i, t-1}+\varepsilon_{t}$. Regressions use least squares estimation with asymptotic GMM standard errors (not reported) that are robust to heteroskedasticity (Hansen, 1982). ${ }^{\dagger}$ Average trading volume per day in million SEK. $¥$ Average of the 62 individual estimates. Reported significance levels tests whether the mean is different from zero using the sample standard deviation (in parentheses). ${ }^{* *} /{ }^{*} /{ }^{\circ}$ Significantly different from zero at the $0.01 / 0.05 / 0.10$ level. 


\section{References}

Abhyankar, Abhay H., "Return and Volatility Dynamics in the FT-SE 100 Stock Index and Stock Index Futures Markets," Journal of Futures Markets, 1995, 15 (4), 457-488.

_ , "Does the Stock Index Futures Market Tend to Lead the Cash? New Evidence from the FT-SE 100 Stock Index Futures Market," 1996. Working Paper 96-01, University of Sterling, Department of Accounting and Finance.

Admati, Anat R. and Paul Pfleiderer, "A Theory of Intraday Patterns: Volume and Price Variability," Review of Financial Studies, 1988, 1 (1), 3-40.

Atchison, Michael D., Kirt C. Butler, and Richard R. Simonds, "Nonsynchronous Security Trading and Market Index Autocorrelation," Journal of Finance, March 1987, 42 (1), 111-118.

Berglund, Tom and Eva Liljeblom, "Market Serial Correlation on a Small Security Market: A Note," Journal of Finance, December 1988, 43 (5), 12651274 .

_ and _, "The Impact of Trading Volume On Stock Return Distributions: An empirical analysis," Finnish Economic Papers, 1990, 3 (2), 108-123.

Boudoukh, Jacob, Matthew P. Richardson, and Robert F. Whitelaw, "A Tale of Three Schools: Insights on Autocorrelations of Short-Horizon Stock Returns," Review of Financial Studies, Fall 1994, 7 (3), 539-573.

Campbell, John Y., Sanford J. Grossman, and Jiang Wang, "Trading Volume and Serial Correlation in Stock Returns," Quarterly Journal of Economics, November 1993, pp. 905-939.

Chan, Kalok, "A Further Analysis of the Lead-Lag Relationship Between the Cash Market and Stock Index Futures Markets," Review of Financial Studies, 1992, 5 (1), 123-152.

_ , "Imperfect Information and Cross-Autocorrelation among Stock Prices," Journal of Finance, September 1993, 48 (4), 1211-1230.

_ , K. C. Chan, and G. Andrew Karolyi, "Intraday Volatility in the Stock Index and Stock Index Futures Market," Review of Financial Studies, 1991, 4 (4), 657-684.

Cohen, Kalman J., Gabriel A. Hawawini, Steven F. Maier, Robert A. Schwartz, and David K. Whitcomb, "Implications of Microstructure Theory for Empirical Research on Stock Price Behaviour," Journal of Finance, May 1980, 35 (2), 249-257.

Fischer, Lawrence, "Some New Stock Market Indexes," Journal of Business, 1966, 39, 191-225.

Foster, F. Douglas and S. Viswanathan, "The Effect of Public Information and Competition on Trading Volume and Price Volatility," Review of Financial Studies, 1993, (1), 23-56. 
Grossman, Sanford J. and Joseph E. Stiglitz, "On the Impossibility of Informationally Efficient Markets," American Economic Review, 1980, 70, 393-408.

Handa, Puneet and Robert A. Schwartz, "Limit Order Trading," Journal of Finance, December 1996, 51 (5), 1835-1861.

Hansen, Lars Peter, "Large Sample Properties of Generalized Method of Moments Estimators," Econometrica, July 1982, 50 (4), 1029-1054.

Harris, Lawrence and Joel Hasbrouck, "Market Vs. Limit Orders: The SuperDot Evidence on Order Submission Strategy," Journal of Financial and Quantitative Analysis, June 1996, 31 (2), 213-231.

Hellwig, Martin F., "On the Aggregation of Information in Competitive Markets," Journal of Economic Theory, 1980, 22, 477-498.

Hussman, John P., "Market Efficiency and Inefficiency in Rational Expectations Equilibria," Journal of Economic Dynamics and Control, 1992, 16, 655-680.

Kahneman, Daniel and Amos Tversky, "Prospect Theory: An Analysis of Decision under Risk," Econometrica, March 1979, 47 (2), 263-91.

Kyle, Albert S., "Continuous Auctions and Insider Trading," Econometrica, 1985, 53 (6), 1315-1335.

_ , "Informed Speculation with Imperfect Competition," Review of Economic Studies, 1989, 56, 317-356.

Lo, Andrew W. and A. Craig MacKinlay, "An Econometric Analysis of Nonsynchronous Trading," Journal of Econometrics, 1990, 45, 181-211.

_ and _ , "When Are Contrarian Profits Due to Stock Market Overreaction?," Review of Financial Studies, 1990, 3 (2), 175-205.

McInish, Thomas H. and Robert A. Wood, "Autocorrelation of Daily Index Returns: Intraday-to-Intraday versus Close-to-Close Intervals," Journal of Banking and Finance, 1991, 15, 193-206.

McQueen, Grant, Michael Pinegar, and Steven Thorley, "Delayed Reaction to Good News and the Cross-Autocorrelation of Portfolio Returns," Journal of Finance, July 1996, 51 (3), 889-919.

Mech, Timothy S., "Portfolio Return Autocorrelation," Journal of Financial Economics, 1993, 34, 307-344.

Miller, Merton H., Jayaram Muthuswamy, and Robert E. Whaley, "Mean Reversion of Standard \& Poor's 500 Index Basis Changes: ArbitrageInduced Or Statistical Illusion?," Journal of Finance, June 1994, 49 (2), 479 513 .

Nordén, Lars, "Handels- och ickehandelseffekter i OMX-index: Är den underliggande processen kontinuerlig?," Beta, 1992, (1), 36-46. 
_, "Daily Distribution of Swedish OMX-Index Returns over Intraday-toIntraday Time Intervals," Finnish Economic Papers, Spring 1994, 7 (1), 3-16.

Richardson, Matthew and Tom Smith, "A Unified Approach to Testing for Serial Correlation in Stock Returns," Journal of Business, 1994, 67 (3), 371-399.

Roll, Richard, "A Simple Implicit Measure of the Effective Bid-Ask Spread in an Efficient Market," Journal of Finance, September 1984, 39 (4), 1127-1139.

Säfvenblad, Patrik, "Lead-Lag Effects When Prices Reveal Cross-Security Information," Working Paper No. 189, Working Paper Series in Economics and Finance, Stockholm School of Economics 1997.

_ , "Learning the True Index Level: Index Return Autocorrelation in an REE Market," Working Paper No. 190, Working Paper Series in Economics and Finance, Stockholm School of Economics 1997.

Scholes, Myron and Joseph T. Willams, "Estimating Betas from Nonsynchronous Data," Journal of Financial Economics, December 1977, 5 (3), 309-327.

Sentana, Enrique and Sushil Wadhwani, "Feedback Traders and Stock Return Autocorrelation: Evidence from a Century of Daily Data," Economic Journal, March 1992, 102, 415-425.

Stoll, Hans R. and Robert E. Whaley, "The Dynamics of Stock Index and Stock Index Futures Returns," Journal of Financial and Quantitative Analysis, December 1990, 25 (4), 441-468. 